\title{
A paz pela escola e as contribuições da Psicologia para os ideais da pedagogia pacificadora
}

\section{Resumo}

Clarice Moukachar Batista Loureiro

Raquel Martins de Assis

Universidade Federal de Minas Gerais

artigo apresenta um conjunto de discussões sobre as relações entre educação para a paz e psicologia elaboradas, ao final da década de 1920, por pesquisadores ligados ao Instituto Jean-Jacques Rousseau/Suíça. A partir do método descritivo-analítico, destacamos as teorias e técnicas levantadas ao longo da conferência $A$ paz pela escola realizada em 1927 pelo Bureau Internacional de Educação, órgão ligado ao Instituto. Demonstramos como os conferencistas desse encontro conceberam a Psicologia como uma ciência central nas propostas de pedagogia pacificadora. Destacamos as concepções de Pierre Bovet sobre os instintos combativos e sociais, teoria psicológica que pretendia orientar o trabalho dos educadores que visavam a um ideal pacifista. Concebemos esse movimento como um projeto civilizatório, fundamentado, sobretudo, no conhecimento científico do ser humano. Para Pierre Bovet, a educação moral, social e religiosa deveria ser os três pilares da pedagogia pacificadora, contrapondo-se a outros cientistas da época, como Jean

74 Piaget.

Palavras-chave: Educação para a paz. Pierre Bovet. Psicologia.

\section{Peace through school and the contributions from Psychology to the aims of the pacifying pedagogy}

\section{Abstract}

This article presents a set of discussions about the relationship between education for peace and Psychology developed in the end of the 1920's by researchers at the Jean-Jacques Rousseau Institute/Switzerland. Based on an analytical-descriptive method, we have brought to notice the theories and techniques raised throughout the conference Peace through the School held in 1927 sponsored by the International Bureau of Education, which was linked to the Institute. We have shown how the speakers at this meeting conceived Psychology as a central science in the proposals for a pacifying pedagogy. Furthermore, we have highlighted Pierre Bovet's concepts on the combative and social instincts, a psychological theory that intended to guide the work of educators who aimed to reach a pacifist ideal. We understood this movement as a civilizing project, based primarily on the scientific knowledge about human beings. Pierre Bovet stated that the moral, social and religious education should be the three standing pillars for the pacifying pedagogy, in contrast to other scientists of the time, such as Jean Piaget.

Keywords: Education for Peace. Pierre Bovet. Psychology. 


\section{La paz en la escuela y las aportaciones de la Psicología para los ideales de la pedagogía pacificadora}

\section{Resumen}

El artículo presenta un conjunto de discusiones sobre las relaciones entre la educación para la paz y psicología elaboradas a fines de la década de 1920, por investigadores vinculados al Instituto Jean-Jacques Rousseau/Suiza. A partir de lo método descriptivo-analítico, destacamos las teorías y técnicas planteadas a lo largo de la conferencia La Paz por la Escuela realizada en 1927 por Bureau Internacional de Educación, órgano vinculado al Instituto. Demostramos cómo los conferencistas de este encuentro concibieron la Psicología como una ciencia central en las propuestas de pedagogía pacificadora. Destacamos las concepciones de Pierre Bovet sobre los instintos combativos y sociales, teoría psicológica que pretendía orientar el trabajo de los educadores que perseguían un ideal pacifista. Concebimos este movimiento como un proyecto civilizatorio, fundamentado, sobre todo, en el conocimiento científico del ser humano. Para Pierre Bovet la educación moral, social y religiosa deberían ser los tres pilares de la pedagogía pacificadora, contrarrestando a otros científicos de la época, como Jean Piaget. Palabras clave: Educación para la paz. Pierre Bovet. Psicología.

\section{Introdução}

Na primeira metade do século XX, o Instituto Jean-Jacques Rousseau (IUR), fundado por Édouard Claparèdee com sede em Genebra - Suíça, tornou-se, inclusive para o Brasil, uma importante instituição devido às suas ações no campo da psicologia e da educação. Em 1925, o IJIR criou o Bureau Internacional de Educação (BIE) cujo principal objetivo era desenvolver estudos de cunho estritamente científico e de neutralidade política, filosófica, religiosa e nacionalista para a promoção da paz e a cooperação internacional pela educação, tendo como pano de fundo o diálogo entre as nações (PARRAT-DAYAN, 2008).

Dirigido, inicialmente, por Pierre Bovete amparado por outros pesquisadores suíços ligados ao IJR, o BIE realizou ao final da década de 1920 uma série de ações voltadas para a divulgação de um ideal de educação para a paz. Confrontados com as tensões políticas da época, esse grupo de 
A paz pela escola e as contribuições da Psicologia para os ideais da pedagogia pacificadora

intelectuais colocava o problema de como educar as crianças de modo que elas escolhessem outras vias para a resolução de conflitos que não o embate físico.

$\bigcirc$ primeiro evento promovido pelo BIE, em 1927, foi a conferência internacional A paz pela escola, em parceria com a Sociedade Pedagógica Comenius da cidade de Praga, na antiga Checoslováquia, hoje República Checa. Reuniram-se nesse evento intelectuais, cientistas, ativistas, profissionais da educação e pais em torno do tema central da educação para a paz.

Neste artigo descreveremos como os conferencistas desse encontro conceberam a psicologia como uma ciência central nas propostas de pedagogia pacificadora. Daremos destaque às concepções de Pierre Bovet sobre os instintos (instincts) combativos e sociais, teoria psicológica que pretendia orientar o trabalho dos educadores que visavam a um ideal pacifista.

Formado em Letras e Filosofia, Pierre Bovet foi diretor do IJIR de 1912 a 1933 e do BIE de 1925 a 1929. Nascido em 5 de junho de 1878, na cidade de Grandchamp, França, provavelmente Bovet herdou o interesse pelo campo da educação de seus pais, que dirigiam estabelecimentos educativos em sua cidade natal, aplicando a filosofia dos Irmãos Moraves. $\bigcirc$ pai de 76 Bovet era professor de Teologia (HOFSTETTER; RATCLIF; SCHNEUWLY, 2012). Seu histórico familiar, marcado pelo protestantismo, pode nos indicar a razão de encontrarmos concepções do cristianismo social nas teorias psicológicas por ele apresentadas, como veremos a seguir.

$\bigcirc$ trabalho pedagógico de Bovet tinha como principal objetivo a construção de uma sociedade solidária e pacífica. Para ele, era imprescindível que o IJJR e o BIE se envolvessem na militância por ideais educacionais que promovessem sociedades democráticas, justas e de direitos iguais. Pierre Bovet e Oskar Pfister foram os primeiros pesquisadores em psicologia, na Suíça, a se apropriar da psicanálise no campo da educação (HOFSTETTER; RATCLIF; SCHNEUWLY, 2012). Daí Bovet ter elegido o tema dos instintos humanos para a sua apresentação na conferência $A$ paz pela escola. Como muitos outros palestrantes, ele defendeu a ideia da existência de uma questão de ordem psicológica a ser tratada no campo da educação para a paz.

Além disso, à época da conferência, Bovet já havia desenvolvido um vasto trabalho sobre a chamada psicologia afetiva - ou psicologia do sentimento - que apostava na possibilidade de, através das interações interpessoais, 
formar a consciência e influenciar os sentimentos dos indivíduos, sobretudo dos escolares. $\bigcirc$ posicionamento de Bovet sobre o cristianismo também tornava o seu trabalho singular. Rochedieu (1967), estudioso da obra de Pierre Bovet e seu contemporâneo, afirmou em um obituário redigido por ele e dedicado ao cientista, publicado dois anos após a sua morte:

É precisamente aos problemas da vida afetiva que Pierre Bovet consagrou seus principais trabalhos, empregando sua vasta experiência pedagógica e seu conhecimento das técnicas psicológicas para desvendar os segredos das realidades morais e religiosas (ROCHEDIEU, 1967, p. 166, tradução nossa)'.

Considerando que a psicologia afetiva aliada às questões morais e/ou religiosas era evocada por esse grupo de intelectuais para fundamentar práticas educacionais voltadas para um ideal de paz (LOUREIRO, 20 15 ), entendemos que as propostas de Bovet realizadas na conferência A paz pela escola podem nos trazer esclarecimentos sobre as formas de conceber teorias psicológicas no final da década de 1920 em suas relações com a educação. Desse modo, partimos do pressuposto de que a psicologia pode ser entendida como uma forma cultural elaborada em contextos a partir dos quais se produzem discursos sobre o ser humano e sua educabilidade (VIDAL, 2003; ASSIS, 20111.

Para este artigo, utilizamos como fonte de pesquisa o documento que compila as exposições realizadas ao longo da conferência e os relatórios enviados por alguns dos participantes ao comitê de organização do evento, a fim de contribuir para as discussões da época. Trata-se de uma publicação organizada pelo próprio BIE e impressa no mesmo ano, logo após a realização da conferência, em versões em esperanto, checo, alemão e francês. A publicação tinha como objetivo tornar disponível as discussões suscitadas para aqueles que se interessavam pelo assunto e não puderam comparecer ao evento realizado na cidade de Praga entre os dias 16 e 20 de abril de 1927 (BOVET, 1927).

Analisamos uma cópia dessa publicação em francês, disponível no Centro de Documentação e Pesquisa Helena Antipoff da Universidade Federal de Minas Gerais em Belo Horizonte, onde encontramos um acervo de grande importância para a história da educação e da psicologia. Os estudos dessa área do conhecimento apontam para uma forte influência do IJJR 
A paz pela escola e as contribuições da Psicologia para os ideais da pedagogia pacificadora

no desenvolvimento da psicologia e da pedagogia brasileira por meio da divulgação de trabalhos de renomados cientistas e educadores ligados ao Instituto como Édouard Claparède, Jean Piaget, Helena Antipoff e Artus Perrelet (RUCHAT, 2008; ASSIS; ANTUNES, 2014; CAMPOS; NEPOMUCENO, 2006; ALMEIDA, 2013 ), inclusive no período quando se iniciam as discussões sobre a educação para a paz na Europa.

É interessante destacar também que discussões sobre projetos educacionais voltados para a promoção da solidariedade e da tolerância à diversidade, presentes nos discursos de 1927 na Europa, encontram lugar nas discussões atuais sobre a educação brasileira que se vê impelida a lidar com os altos índices de violência dentro das escolas e com os impasses colocados à educação inclusiva (ABRAMOVAY; RUA, 2002). Entendemos assim que este estudo pode contribuir não somente para a história da psicologia e da pedagogia, mas também para as elaborações atuais sobre a construção de projetos escolares calcados em ideais de paz e de inclusão (DELORS, 2010).

Em termos metodológicos, a análise da documentação foi realizada pelo método descritivo-analítico, conforme apresentado por Pongratz (1998), procedimento segundo o qual a descrição, fundamentada na leitura das fontes,

78 é suplementada pela análise realizada pelo pesquisador, levando em consideração o contexto sociocultural da época e do local onde a teoria de Pierre Bovet foi divulgada.

Apresentaremos a conferência A Paz pela Escola, descrevendo sua organização, as concepções que a sustentaram e as relações estabelecidas entre psicologia e educação. Em seguida, trataremos dos saberes em psicologia divulgados por Pierre Bovet durante o evento, levando em consideração a ênfase na psicologia dos sentimentos e dos instintos combativos e sociais.

\section{A conferência A paz pela escola}

Desde a sua criação, o BIE permanecia ligado ao IJR. Assim, as duas instituições compartilhavam as mesmas causas, dividiam o mesmo espaço físico e tinham os mesmos intelectuais à frente dos seus trabalhos. No entanto, era interesse do IJIR que o BIE se tornasse autônomo da sua instituição de origem já que, por se tratar de um órgão internacional, ele deveria ser amplamente conhecido e conquistar apoio e legitimidade diante das instituições pedagógicas de outras nações. Por esse motivo, o nome do IJRR pouco aparece nos textos 
analisados apesar de os organizadores do evento, e os temas discutidos, estarem diretamente relacionados às atividades realizadas pelo Instituto.

projeto de tornar o BIE uma instituição que se afirmasse para "além dos muros" da Suíça pode ser evidenciado pelos calorosos agradecimentos, feitos na conferência, ao ministro da Instrução Pública e ao presidente da Checoslováquia, respectivamente Milan Hodza e Thomas Masaryk, ambos ícones do pacifismo. O movimento pacifista eslovaco conservava ideais datados do século XVII, representados pelo pensador Jean Amos Comenius², e estava fortemente representado tanto por participantes quanto por conferencistas do evento realizado pelo BIE.

Além do público da Checoslováquia, diversos países enviaram seus representantes: Áustria, Bulgária, Bélgica, Dinamarca, Espanha, Inglaterra, Holanda, Itália, Polônia, Portugal, Romênia, Suécia, Turquia, Suíça, França, Alemanha, Estados Unidos, Brasil e País de Gales. A participação do Brasil foi marcada pela presença e colaboração do ex-diretor do Ensino Primário do Rio de Janeiro, Antônio Carneiro Leão, cujo relatório das atividades relacionadas à educação internacional, realizadas ao longo de seu mandato, faz parte do registro do evento ${ }^{3}$.

Além da variedade de nacionalidades presentes, a conferência reuniu pessoas, oriundas de diversos setores da sociedade. Pais, alunos, educadores, intelectuais e governantes compunham um público bastante heterogêneo. Para Bovet, o sucesso dessa reunião se deveu, principalmente, pelo interesse dos participantes pela discussão do tema, já que o evento foi uma das primeiras ações organizadas pelo BIE e não contou com nenhum recurso para sua execução (BOVET, 1927).

Apesar da avaliação positiva feita por Bovet quanto à repercussão da Conferência, Magnin (2002) ponderou que a maioria dos participantes não possuía representatividade política. Tratava-se de um evento organizado essencialmente por intelectuais, cientistas e militantes pacifistas e esperantistas. De fato, os conteúdos trabalhados nos demonstram um enfoque científico e ativista, conforme a tendência do BIE e do IJIR nesse período da década de 1920 (LOUREIRO, 2015).

Na carta convite, enviada em março de 1927 - assinada pelo presidente e secretária-geral do BIE, respectivamente Pierre Bovet e Marie Butts, e pelo presidente e secretário do comitê de organização do congresso, Vaclav 
A paz pela escola e as contribuições da Psicologia para os ideais da pedagogia pacificadora

Prihoda (Genebra/Suíça) e Joseph Ogoun (Praga/Checoslováquia) - ficou estabelecido que os palestrantes escolheriam a língua para exposição dos trabalhos, que seriam traduzidos em esperanto nas chamadas sessões de trabalho e em checo nas sessões destinadas ao público de Praga.

Segundo a documentação analisada, o evento era destinado a "[...] estudar sucessivamente os dados psicológicos indispensáveis para fundamentar o trabalho assim como apresentar algumas das soluções propostas ou já colocadas em prática para alcançar um resultado positivo pelo ensino e pela educação como um todo" (BOVET, 1927, p. 5, tradução nossa)4

Considerando este objetivo, o programa da conferência A paz pela escola se organizou em torno de três grandes áreas: Psicologia, Ensino e Educação para a paz. Cada uma dessas áreas constituiu uma sessão de trabaIho aberta ao público quando os conferencistas proferiam suas contribuições. Foram formadas três comissões, uma para cada sessão e cada uma dessas comissões se reuniu ao final do encontro para a construção das resoluções da conferência relativas a cada uma das grandes áreas. No entanto, segundo Jares (2002), o assunto de maior repercussão foram as teorias psicológicas apresentadas por Pierre Bovet sobre o instinto de luta ou instinto combativo.

Os intelectuais presentes na conferência entendiam que a busca pela paz entre os povos deveria partir do desenvolvimento do espírito de cooperação internacional. Embora a psicologia fosse um dos temas mais promovidos pela conferência, a discussão sobre a cooperação internacional era concebida como sendo também de ordem moral, social e religiosa, pois, para suscitar o espírito cooperativo, era necessário considerar os diversos aspectos implicados na integralidade da criança. Nessa tarefa, a ciência e a própria criança eram vistas como aliadas.

A psicologia era considerada central para a promoção da educação para a paz por ser a ciência cujo objeto era o espírito humano e suas faculdades psíquicas. Esperava-se que ela fornecesse elementos para a intervenção sobre as energias individuais, base da promoção do espírito de cooperação internacional. Conforme registrou Parrat-Dayan (2008, p. 59), para Claparè de "A educação para a paz [...] deveria ser feita através do estudo das condições psicológicas que favoreceriam a emergência de atitudes pacifistas, de um lado, ou nacionalistas, de outro, com tendência à intolerância e, portanto, contrárias à promoção da paz entre as nações". 
Essa centralidade se confirmava na avaliação, realizada por Bovet, das experiências de educação para a paz comunicadas pelos conferencistas, registrada em 1928 em outra publicação do BIE: "É facilmente visível que as diversas experiências práticas experimentadas pelos conferencistas no campo da educação para a paz se inspiram em observações psicológicas ou chegam à conclusões desta ordem"(BIE, 1928, p. 10, tradução nossa). ${ }^{5}$

Assim, o próprio Pierre Bovet, apresentou na sessão de Psicologia da conferência, a exposição "Alguns problemas psicológicos da educação para a paz"b sobre o qual discorreremos adiante. Juntamente com Bovet, trouxeram suas contribuições para a sessão de Psicologia o professor da Universidade de Harvard nos Estados Unidos, D. A. Prescott e o diretor de um ginásio de Brno, cidade da República Checa, Rodolphe Fridrich.

Prescolt apresentou o trabalho intitulado "O estudo científico das posturas e preconceitos das crianças: métodos e resultados"7 descrevendo três tipos de procedimentos para a avaliação da influência do ensino sobre os comportamentos e sobre os preconceitos das crianças. Já Rodolphe Fridrich contribuiu com a divulgação do "Questionário sobre os sentimentos das crianças relativos à paz e a guerra aplicado a 143 crianças e adolescentes checos em fevereiro e março de 1927"8, investigação realizada exclusivamente para a Conferência.

Durante a Conferência, a comissão que formava a sessão de psicologia, reunida em assembleia, debateu a importância do ensino das teorias psicológicas nos cursos de formação de professores. Ressaltava-se, principalmente, a utilidade da psicologia dos sentimentos por oferecer elementos para formação da consciência dos alunos. As teorias psicológicas, portanto, eram consideradas uma importante contribuição para o aperfeiçoamento da educação moral, contanto que as práticas educacionais adotadas fossem subsidiadas pelos saberes oriundos do movimento da Escola Nova, ou seja, pelas concepções de valorização da experiência cotidiana das crianças em detrimento do ensino livresco que serão amplamente debatidas na sessão sobre a Educação para a paz.

A Comissão discutiu também a inconveniência das conclusões precipitadas de testes de inteligência comparada entre os diferentes povos, criticando nitidamente as tendências à eugenia já manifestadas por alguns países nesse período e que teriam um papel fundamental durante a Segunda 
A paz pela escola e as contribuições da Psicologia para os ideais da pedagogia pacificadora

Guerra Mundial. É possível identificar os interesses do BIE em buscar métodos de avaliação psicológica que pudessem considerar em que medida os comportamentos humanos seriam provenientes do meio ou do caráter das crianças.

Na discussão do impacto dos fatores ambientais sobre o comportamento e a construção do espírito infantil, a Comissão procurava, sobretudo, analisar os modos pelos quais a educação da época influenciava a origem e o desenvolvimento dos problemas internacionais. Para isso, apresentavam estudos que, permeados pela díade inato/adquirido, discutiam o ensino de tipo internacionalista ou nacionalista recebido pelos escolares.

A sessão da Conferência sobre o Ensino contava com a participação de diversos expositores centrados principalmente no tema da revisão dos manuais de história. Duas posições conflitantes sobre o ensino de história são apresentadas: a primeira, amplamente combatida pelos participantes do evento, enfatizava a narração das guerras, o heroísmo militar e a vaidade nacional. Considerava-se que essa vertente incentivava o ódio aos povos estrangeiros, já que, no contexto da época, havia uma forte pressão para que os cidadãos valorizassem a própria nacionalidade em detrimento dos diálogos internacionais (HOBSBAWM, 1995). Contrariamente a essa concepção

82 de ensino, os pacifistas defendiam a função moral da história e o ensino por meio de figuras exemplares, isto é, a valorização de personagens que lutaram pela paz e combateram conflitos e interesses que levavam a soluções bélicas.

Ideias pacifistas deveriam ser disseminadas nas escolas não através da criação de uma nova disciplina, mas aplicadas aos conteúdos já trabalhados. "Não se trata de um novo ramo, mas de um novo espírito", afirmou Marcel Du Pasquier (1927, p. 64), expositor na conferência. Para o desenvolvimento do espírito de cooperação internacional entre os escolares, Zdenek Franta (1927), inspetor das escolas secundárias de Praga, propunha:

Os manuais de história e os professores ensinarão também à juventude que o pacifismo não é composto de suspiros sentimentais; não se trata de fechar os olhos diante da realidade desagradável, é um trabalho sistemático e audacioso; ele não significa somente a guerra contra a guerra mas vai além, significa a guerra contra tudo o que conduz à guerra (FRANTA, 1927, p. 52, tradução nossa) ${ }^{10}$.

Além de combaterem os diversos aspectos que favoreciam as situações de guerra, os pacifistas frequentemente se defendiam de uma crítica a 
eles direcionada, de certo sentimentalismo em suas proposições de paz, como é possível perceber na citação acima. Por esse motivo, eles afirmavam também que os manuais de história deviam ensinar os países a se preparar para o confronto físico, caso fosse inevitável. Os manuais escolares, portanto, teriam a difícil missão de construir o espírito de diálogo e de paz, mas, ao mesmo tempo, ensinar às crianças e aos jovens que a Pátria deveria se defender contra a violência dos agentes externos.

Entre as principais resoluções discutidas pela comissão responsável pela sessão de Ensino presidida por Joseph Ogoum, secretário da conferência, ressaltamos: a afirmação do ensino para a paz como um conteúdo transversal a todas as disciplinas e não como um novo ramo do conhecimento; a necessidade de o ensino de História ser permeado por um espírito favorável à paz; o papel do BIE na oferta constante de oportunidades para a construção de propostas de educação para a paz a partir de bases políticas, econômicas e sociais; a recomendação para que os governos dos países facilitassem o intercâmbio de professores e alunos; e novamente, assim como recomendado na sessão de Psicologia, a utilização dessa ciência aliada aos princípios da Escola Nova para formação de consciência e educação dos sentimentos.

Esses princípios foram também amplamente discutidos na sessão de Educação atravessando, portanto, todas as sessões que compunham o programa da Conferência. Além dos intensos debates sobre os princípios da Escola Nova, recomendou-se vivamente o método da correspondência internacional, o ensino de esperanto e a possibilidade de realização de acampamentos internacionais.

método da correspondência internacional visava se contrapor às técnicas, adotadas na época, de exposição das crianças a cenas detalhadas de mortes ou de destruição resultante dos conflitos a fim de provocar horror à guerra. Consistia basicamente em favorecer a troca de correspondências e de material escolar entre crianças de diferentes países. A proposição dessa atividade ancorava-se na ideia de que o patriotismo não era contrário ao internacionalismo e para que houvesse compreensão entre os povos era necessário conhecer as particularidades de cada um.

Outro argumento para a utilização desse método tomava por base as ideias da Escola Nova, segundo as quais era importante aproximar os conteúdos de aprendizagem da vida cotidiana das crianças. Para esses educadores, 
A paz pela escola e as contribuições da Psicologia para os ideais da pedagogia pacificadora

"[...] as experiências são mais convincentes que as palavras"11 (BOVET, 1927, p. 96), por isso a atividade da criança deveria ser valorizada em detrimento do ensino pautado pela simples transmissão de conteúdos. Assim, no campo da educação internacional, a experiência de correspondência epistolar entre crianças de nacionalidades diferentes, além de promover o conhecimento da cultura de outro país, levaria os escolares aos sentimentos de amizade e de desejo de paz com os estrangeiros. Esse desejo deveria ser estimulado desde a tenra infância ${ }^{12}$.

Antonio Carneiro Leão, representante do Brasil na conferência, relata em seu relatório enviado à comissão de organização que a utilização do método da correspondência internacional estava entre os objetivos estabelecidos para desenvolver uma educação internacional nas escolas brasileiras quando foi diretor-geral da instrução pública primária, normal e profissional no Rio de Janeiro.

Outra estratégia para a educação da paz amplamente divulgada na conferência foram os acampamentos internacionais da juventude. Promovidos principalmente pelas Unions Chrétiennes de Jeunes Gens (Y.M.C.A.), esses encontros se propunham a reunir uma centena de jovens de diferentes nacio84 nalidades em um ambiente campestre onde era possível a prática de esportes, jogos, reuniões em volta de fogueiras, entre outras atividades. Os adolescentes, provenientes de diferentes países, eram incentivados a ficar alojados em cabanas a fim de estabelecer experiências concretas de contato com outras culturas, quebrando as barreiras do desconhecimento e do preconceito. Os próprios adolescentes eram convidados a escolher os temas a serem discutidos nas grandes assembleias, sendo que assuntos como a guerra e as diferenças religiosas eram constantemente evocados. Esses encontros tinham como objetivo principal formar cidadãos do mundo capazes de influenciar suas cidades e seus países natais a estabelecer boas relações entre as diferentes nações.

Assim, ficava evidente como os princípios da Escola Nova, associados ao conhecimento da Psicologia da criança, eram a base de apoio para os métodos recomendados na educação das novas gerações. Colocar a criança ou o jovem como protagonista da aprendizagem, priorizar a experiência no lugar da transmissão de conhecimento, incentivar o trabalho em grupo eram concepções divulgadas incansavelmente. Na Conferência, o professor holandês R. Casimir (1927, p. 75, tradução nossa), afirmava que o método direto, ou self-government, promovia nos jovens o respeito pela lei e a prática da 
justiça, aspectos importantes para a educação fundamentada nos ideais de paz, afirmando que "[...] antes de chegar ao verdadeiro internacionalismo, é necessário inicialmente estimular os sentimentos de justiça, de cooperação, de submissão dos interesses egoístas a um objetivo geral. É aí que se encontra a relação entre o self-government e o movimento pacifista" ${ }^{\prime 3}$.

Apoiando-se na ideia de John Dewey de que a escola não deveria ser uma preparação para a vida, mas a própria vida do aluno, Casimir relatou experiências com associações de jovens estudantes organizadas dentro da escola a partir do método do self-government. Nessas associações, os escolares eram direcionados a construir suas próprias leis de funcionamento e a obedecê-las, além de assumirem um papel ativo na vida social da escola. A psicologia da adolescência era evocada para esse tipo de trabalho. Segundo Casimir, o adolescente aspira a um reconhecimento e deseja servir a um ideal mas, contraditoriamente, na sua vida cotidiana, ele não é incentivado a se engajar em nenhuma causa, pois seu único trabalho é obter notas boas na escola.

A adolescência, portanto, precisava ser considerada pelos educadores como uma fase de agudas aspirações morais, religiosas e idealistas a serem contempladas nas associações escolares. Assim, o adolescente era apontado como principal alvo da educação e evidenciava-se a importância da educação para a paz entre 14 e 18 anos, idade em que seriam definidos pontos de vista cuja influência apareceria, mais tarde, na vida universitária e na vida adulta.

Ao lado da formação do adolescente, a Comissão de Educação ressaltou a importância de ações dirigidas aos grupos minoritários presentes nas escolas a fim de incentivar o respeito e a prática da justiça. Essas ações, quando propostas dentro dos limites escolares, poderiam contribuir para lidar com o problema, sempre presente na história da humanidade, do respeito aos direitos das minorias.

Diante dessas diversas discussões, a comissão da sessão de educação, presidida por Pierre Bovet, afirmou o incentivo à autonomia dos estudantes por meio das associações e comunidades escolares com criação de regimentos internos e formação de tribunais estudantis para a resolução de conflitos. Esse grupo também elaborou uma demanda à Sociedade das Nações para 
A paz pela escola e as contribuições da Psicologia para os ideais da pedagogia pacificadora

interceder junto aos governos a fim de facilitar intercâmbios de professores e alunos e a correspondência internacional interescolar.

Além das sessões de trabalho - Psicologia, Ensino e Educação para a paz - a conferência promoveu duas exposições noturnas sobre temas educacionais destinadas ao público de Praga, ocorridas nos dias 18 e 19 de abril, às 20 horas, em Checo. Essas sessões noturnas apresentaram recortes da história do pacifismo na República Checa. Segundo os autores, o movimento pacifista, nesse país, havia se iniciado no século XVI com o surgimento da União dos Irmãos Checos, fruto da reforma protestante realizada por Jean Hus $^{14}$.

Os Irmãos Checos viviam o chamado cristianismo social, uma espécie de filosofia doutrinária segundo a qual a democracia e a fraternidade mundial são ideias fundamentais da paz que devem permanecer vivas por meio da literatura, da arte e da filosofia. Considerando o Pai celeste como a maior autoridade existente, o cristianismo social tendia a não legitimar as autoridades constituídas por homens e combatia a violência, a guerra e o militarismo. Hendrich (1927, p. 108) resumiu o ideal do cristianismo social da seguinte forma: "[...] o amor à paz e o horror à violência, esta era a tradição da 86 Unidade dos Irmãos Checos" ${ }^{\prime 15}$.

Como veremos a seguir, além de se inspirar na psicanálise, Bovet também se ancorava em elementos do cristianismo social para fundamentar suas discussões sobre as relações entre psicologia e educação para a paz. Desse modo, é possível entender os motivos que levaram Pierre Bovet a se unir à Sociedade Pedagógica Comenius para a realização da primeira Conferência do BIE na cidade de Praga, lugar onde o então presidente da República Checa, Thomas Masarick, tinha seu programa de governado orientado pelos ideais pacifistas originados do cristianismo social.

\section{A teoria dos instintos combativo e social de Pierre Bovet apresentada na conferência}

Pierre Bovet foi convidado por Claparède para a direção do IJJR quando da sua inauguração e foi também ele quem dirigiu o BIE de 1925 a 1929. Para ele, a educação moral, as preocupações humanitárias, democráticas e pacifistas deveriam fazer parte do espírito dessas instituições (PARRAT-DAYAN, 2008). No entanto, quando os movimentos de extrema direita 
começaram a se pronunciar nas esferas políticas de Genebra, suas ideias passaram a ser julgadas pelo Departamento de Instrução Pública (DIP) como por demais progressistas. Inicia-se então uma tensão entre o BIE e a DIP que culminou com o pedido para que Bovet "[...] limitasse a sua atividade a uma de intuito científico de ensino e de pesquisa" (PARRAT-DAYAN, 2008, p. 67). Esse pedido contrariou Bovet, que deixou a direção do BIE em 1929 por considerar que ficar sob essas condições seria comportar-se como traidor do espírito militante da instituição.

No entanto, era ele quem dirigia o BIE em 1927 quando a instituição realizou a conferência. Sua exposição discutia os resultados de uma investigação cujo objetivo era saber "[...] quais adversários, quais auxiliares um educador inspirado em um ideal de paz encontraria nas tendências espontâneas da criança, em seus instintos [...]" (BOVET, 1927, p. 29, tradução nossa) $)^{16}$.

Bovet pesquisou o instinto de luta ou de combate, ao longo da guerra, a partir de enquetes realizadas com alunos, analisando-as, sobretudo, a partir de apropriações das teorias dos instintos humanos propostas por Sigmund Freud e William James (HOFSTETTER; RATCLIF; SCHNEUWLY, 2012).

Na conferência, afirmava-se que, caso as crianças fossem ensinadas a não entrar no embate físico entre elas, não haveria mais guerra. Para educá-las, entretanto, era necessário compreender de que modo os embates físicos se relacionavam a instintos naturais intrínsecos aos seres humanos. Bovet afirmava a existência de um instinto nomeado por ele como combativo ou de luta, nome que dará origem a seu livro L'instinct combatif, publicado em 1917 e traduzido para seis outras línguas ${ }^{17}$.

Para esse cientista, esse instinto estaria mais presente entre os meninos do que nas meninas, sobretudo no período que antecede a puberdade. Esse fato levava ao estabelecimento de uma hipótese evolutiva segundo a qual o instinto combativo teria a sua origem nas necessidades primitivas de sobrevivência e reprodução do homem. Apesar de estar ancorado nas necessidades mais primitivas, ele estaria sujeito a repressões sociais tanto quanto o instinto sexual, sendo regrado ou canalizado pela sociedade sob o pretexto de garantir a manutenção da ordem.

Em períodos de guerra, no entanto, segundo Bovet, o Estado moderno tirava proveito dessa tendência instintiva. Aquilo que era proibido fazer 
A paz pela escola e as contribuições da Psicologia para os ideais da pedagogia pacificadora

isoladamente e que causaria um desequilíbrio na ordem social, tornava-se permitido, obrigatório e digno de honra durante a guerra, já que a luta seria realizada em nome e sob a ordem do Estado. Desse modo, o instinto de luta seria satisfeito nos conflitos bélicos. Apesar dessa possibilidade de satisfação oferecida pela sociedade, Bovet discutia que, de fato, para aqueles que vivenciaram a guerra, o conflito nada teve de honroso e, portanto, não poderia oferecer um bem-estar real.

Para sustentar sua teoria sobre a impossibilidade de satisfação real nas guerras, Bovet se apropriou de concepções de William James segundo as quais os instintos poderiam ser alterados conforme o meio em que os indivíduos se inseriam. Às ideias de James, ele uniu argumentos sobre as possíveis vias de canalização desses instintos, apontando para a teoria da sublimação proposta por Freud. Segundo Bovet, os educadores concordavam que é muito mais fácil canalizar os perigos de certos instintos do que procurar reprimi-los absolutamente.

Em suma, Bovet enumerou quatro maneiras de o instinto combativo ser canalizado para situações menos violentas. A primeira delas seria o desvio, isto é, quando o indivíduo se sujeita a um desafio imposto a si mesmo, como 88 o de um alpinista disposto a escalar uma montanha. Assim, todo o esforço muscular e os sentimentos presentes em uma luta corpo a corpo eram preservados no desafio proposto a si próprio. A platonização seria um segundo modo de canalizar o instinto através de uma atividade intelectual, por exemplo, por meio de um debate de ideias e discussões sobre determinados temas como fazia Sócrates nos diálogos de Platão. A objetivação seria alcançada através do interesse na luta dos outros, seja pelo esporte ou pela leitura de histórias de soldados. Por fim, ele propôs a sublimação total, ou seja, a canalização de toda a energia primitiva do instinto para esforços morais, artísticos, científicos ou religiosos.

Na conferência, Bovet afirmou que a perspectiva da sublimação abria a possibilidade de traçar um programa educativo inovador capaz não propriamente de reprimir os instintos de luta das crianças, mas de conduzi-los para atividades socialmente úteis ou aceitáveis. $\bigcirc$ escotismo seria o exemplo de uma prática juvenil que canalizava os instintos combativos dos jovens para atividades saudáveis. As ideias defendidas por Pierre Bovet ofereciam uma síntese entre concepções da Psicanálise, da Psicologia funcional e do próprio movimento psicológico do IJR, fortemente fundamentado nos ideais da Escola 
Nova, na produção de uma proposta adaptativa em psicologia e educação. De fato, educar para a paz significava permitir estratégias sociais que pudessem viabilizar a canalização dos instintos para modos mais adaptados ao ambiente. Nesse viés, as atividades saudáveis e atitudes altruístas e cooperativas eram entendidas como formas mais bem-sucedidas de sublimação dos instintos e de adaptação à sociedade.

A pesquisa apresentada por Bovet também identificava um segundo instinto considerado inato às crianças: a tendência à ajuda mútua e à solidariedade, chamado por ele de instinto social. Este poderia ser observado isolado ou aliado ao instinto combativo. Para Bovet (1927, p. 34), "O exército como um todo poderia ser descrito como uma manifestação do instinto social a serviço do instinto de luta"18, ou seja, a ânsia por servir à sociedade provocada pelo instinto social seria saciada ao mesmo tempo que ocorreria uma canalização da energia primitiva voltada ao combate.

Para ele, os instintos sociais aparecem profundamente enraizados na natureza humana, mas são suscetíveis de evolução. Bovet apresentou uma hipótese evolutiva da natureza humana composta por três formas principais e hierarquizadas de instintos sociais, cada uma delas caracterizada por um sentimento específico de satisfação.

A primeira e mais primitiva seria o instinto gregário, que consiste no prazer experimentado ao estar na coletividade. Esse instinto é dominado pela sensação e pela presença mínima de elementos representativos. A segunda seria o prazer da conformidade que emerge por meio do sentimento de semeIhança com os outros experimentado nos gestos, gostos e crenças comuns. Por fim, a solidariedade, uma forma bem superior do instinto social, seria caracterizada pela abstração como elemento fundamental para levar os indivíduos a enxergarem na diversidade algum elemento comum a todos. A superioridade da solidariedade, em relação aos outros dois instintos, era marcada pela possibilidade de levar os indivíduos a se sentirem bem em um meio diverso do seu próprio. Para Bovet, os seres humanos são caracterizados pela necessidade de experimentar a solidariedade. A maior manifestação desse instinto seria a comunhão espiritual, ou seja, todos reunidos em nome de um Pai celestial, expressão máxima de sublimação do instinto social.

Bovet concebia a comunhão espiritual como fonte de forte carga de emoção, acompanhada da experiência de fraternidade e de presença divina 
A paz pela escola e as contribuições da Psicologia para os ideais da pedagogia pacificadora

representada pelo sentimento de filiação. A partir desse pressuposto, para o filósofo suíço, tanto o sentimento religioso quanto o sentimento patriótico encontravam sua origem no sentimento filial primitivo, outro instinto inato da criança, manifesto ao mesmo tempo pelo amor e pelo temor aos pais.

Nessa perspectiva, a criança de até cinco ou seis anos credita atributos divinos a seus pais. Durante o processo evolutivo do ser humano, esses atributos divinos teriam sido também creditados aos pais primitivos, aos chefes das tribos que reivindicavam adoração e lealdade. Essa lealdade havia originado a devoção absurda e tocante do amor filial. $\bigcirc$ Estado moderno herdara algo dessa lealdade primitiva, dando origem ao patriotismo. As afirmações de Bovet demonstravam o risco que o sentimento patriótico trazia consigo ao levar o indivíduo a uma adoração cega de uma coletividade falha.

A proposta apresentada pelo filósofo suiço para a educação para a paz consistia em desenvolver o sentimento social de modo a direcioná-lo à coletividade, seja ela o grupo de próximos, o Estado ou a humanidade como um todo. Assim, Bovet introduziu, na conferência, o tema do amor à humanidade como elemento importante a ser semeado no coração das crianças. $\mathrm{Na}$ época, a Sociedade das Nações (SDN) discursava sobre as formas de desen90 volver esse sentimento, sobretudo nas crianças e nos jovens.

Bovet julgava que, apesar dos esforços da SDN, ela não possuía recursos simbólicos suficientes, capazes de fazer frente aos países com seus discursos nacionais como, por exemplo, o patriotismo ou o amor à bandeira e ao hino nacional. A saída que ele propôs, portanto, era considerar a religião como o campo que forneceria elementos simbólicos para o fortalecimento do sentimento de cidadão do mundo. Ele justificou isso da seguinte maneira:

Na verdade, nós nunca encontraremos um símbolo da família humana mais bonito, nem mais satisfatório para o espírito e para a fé ao mesmo tempo, que o do Pai celeste. A religião da fraternidade humana não poderia ignorar este símbolo; ela não saberia nem a longo prazo - esta é a nossa convicção - passar sem ele (BOVET, 1927, p. 37, tradução nossa) ${ }^{19}$.

Para Bovet, na história, o nome de Deus foi frequentemente associado às guerras, disputas, ódios, mas isso se devia a visões estreitas da divindade. Ao invés de ser reconhecido como o Pai de todos, os instintos primitivos colaboravam para a representação de Deus como chefe de um clã ou de um pequeno 
rebanho de eleitos. Ele propõe então ensinar que existe um Deus que é universal concluindo que "[...] a educação para a paz me parece supor e implicar, ao mesmo tempo, uma educação moral (a luta contra o mall), uma educação social (uma iniciação à solidariedade), uma educação religiosa (um conhecimento mais alto do pai celeste e da família humana)" (BOVET, 1927, p. 37, tradução nossa) ${ }^{20}$.

Fica então bastante evidente ao final de sua exposição que, além de propor a canalização dos instintos para modos mais adaptados ao ambiente, ele afirmava também a necessidade da educação não apenas religiosa, mas especificamente cristã. A sublimação seria a base da unidade religiosa capaz de suportar o espírito de cooperação internacional. A ciência e a educação, por outro lado, forneceriam instrumentos e métodos que facilitassem os processos de sublimação diante das exigências da cultura.

Concluindo, em sua exposição no congresso de 1927, Bovet defendeu que a psicologia poderia contribuir para os ideais de uma pedagogia pacificadora na medida em que, além de desenvolver os estudos sobre os instintos humanos e seus processos de canalização, lançasse um olhar pragmático sobre eles, o que auxiliaria o professor a promover métodos mais adaptados à promoção de sociedades solidárias. Assim, na escola, o instinto de luta deveria ser canalizado para fins nobres, especialmente pela ação da sublimação, e o instinto social ser desenvolvido até atingir o mais alto nível da solidariedade.

Essas duas estratégias educacionais, cuja base era o desenvolvimento psicológico da criança, levaria à experiência de satisfação diante da diversidade. Por fim, a educação religiosa era proposta por Bovet como o campo mais propenso à construção de recursos simbólicos relacionados ao sentimento de igualdade, paternidade e de amor à humanidade, apontando para a estreita relação entre a sua teoria e as ideias do cristianismo social.

\section{Conclusões}

É interessante notar as questões que se colocam ao campo da Educação quando as sociedades vivenciam um tempo de desespero e tragédia como foi o caso da Primeira Guerra Mundial. Jean Piaget, célebre psicólogo do século XX, afirmou, em 1931, que a educação era o principal meio para auxiliar os homens a se desprenderem de seus antigos pontos de vista para 
A paz pela escola e as contribuições da Psicologia para os ideais da pedagogia pacificadora

se apropriarem de novas formas de pensamento, já que atua em uma escala mais abrangente. Concebida dessa forma, a educação se torna poderosa arma nas mãos daqueles responsáveis pela formação das futuras gerações, possibilitando-thes, inclusive, mudar o curso da história, seja em direção ao desenvolvimento ou à catástrofe.

Entendemos que os organizadores da conferência A paz pela escola compartilhavam dessa mesma opinião e apostavam no trabalho desenvolvido pelas escolas para a divulgação do novo órgão, a SDN, que procurava se afirmar como referência nas relações internacionais. Como aliada à educação, a psicologia se pronunciava como um importante instrumento de conhecimento do funcionamento psíquico, fundamental para o desenvolvimento do espírito internacional almejado.

No entanto, é necessário ponderar sobre a difícil tarefa enfrentada por esse grupo de intelectuais, educadores e também pais que se preocupavam com o tipo de instrução que seus filhos recebiam nas escolas. Buscava-se difundir o pensamento internacionalista entre as crianças e, para isso, recorria-se à ciência para alcançar as profundezas de tal trabalho. No entanto, vivia-se em um contexto de pós-guerra onde as tensões entre os países crescia ao longo da 92 década de 1920, sobretudo considerando a grande depressão econômica iniciada, nesse período, e a ascensão das forças políticas do militarismo e da extrema direita em alguns países como a Alemanha. Segundo Hobsbawn (1995, p. 43), este contexto tornava a ideia de uma nova guerra mundial "[...] não apenas previsível, mas rotineiramente prevista".

Como formar a consciência internacionalista diante de uma ameaça concreta de guerra? Como educar para a tolerância e solidariedade ao estrangeiro quando o próprio estrangeiro é o inimigo? Essas eram questões que não apareciam diretamente nos discursos analisados, mas que puderam ser percebidas nas entrelinhas. Entendemos que a discussão sobre as condições psicológicas que favoreceriam atitudes pacifistas ou nacionalistas se dava em um contexto que reagia aos conflitos herdados do século XIX, ou seja, aos problemas advindos da ascensão de grandes impérios que pouco davam atenção às questões humanitárias implicadas nas relações internacionais.

Tratava-se, portanto, de um projeto civilizatório, fundamentado, sobretudo, no conhecimento científico do ser humano, como bem podemos entender a partir do trabalho de Pierre Bovet. Acreditamos ser importante ressaltar que, 
nessa discussão realizada pouco após a Primeira Guerra Mundial, os três pilares indicados por Bovet como fundamentais para uma educação pacificadora - educação moral, social e religiosa - foram apoiados pela maioria dos conferencistas. No entanto, essa concepção seria bastante criticada ao final da década de 1920 e início da década de 1930, inclusive por Jean Piaget que irá substituir Pierre Bovet na direção do BIE em 1929.

Para Piaget (1998, p. 85), o obstáculo a ser superado para atingir uma educação internacionalista são as tendências espontâneas dos indivíduos, as quais os impulsionam "[...] seja a erigir em absoluto nosso egocentrismo nacional, seja a sonhar com uma humanidade abstrata e ideal. Essas duas atitudes se equivalem, pois o segundo absoluto é no fundo apenas o primeiro, projetado nos céus".

Entendemos que aqui ele marca a sua discordância com a proposta de Pierre Bovet para a educação internacional apresentada no congresso $A$ paz pela escola. Bovet afirmava que a possiblidade de construção do espírito de cooperação internacional supunha uma intervenção específica sobre os instintos humanos que poderia ser colocada em prática pelos métodos de educação para a paz. A educação religiosa seria um dos principais instrumentos desse projeto pedagógico, pois ela levaria ao conhecimento do Pai celestial e ao sentimento de igualdade e amor à humanidade. Piaget tornou-se um crítico de Bovet, ao afirmar que a educação para a paz deveria ser pautada na construção de formas cooperativas de operar sobre a realidade que não passavam pela transcendência do ser e pela necessidade da religiosidade.

Apesar da riqueza de conteúdo dessas discussões, esse movimento vai se enfraquecendo até ser completamente silenciado em 1939 quando inicia a Segunda Guerra Mundial. Ainda assim, entendemos que o tema da educação para a paz, ligado ou não ao internacionalismo, é bastante atual devido ao contexto contemporâneo em que se valoriza o ideal de educação para todos, o respeito à diversidade e os projetos escolares inclusivos. Vivemos momentos históricos diferentes, mas o ser humano e seus modos de operar sobre a realidade podem se assemelhar em alguma medida. Assim, esperamos que as questões levantadas sobre um passado não tão distante possam contribuir, de alguma maneira, para o debate contemporâneo sobre uma educação pacificadora. 


\section{Notas}

1 Or c'est précisément aux problèmes de la vie affective que Pierre Bovet a consacré ses principaux travaux, employant sa vaste expérience pédagogique et sa parfaite maîtrise des techniques psychologiques à pénétrer le secret des réalités morales et religieuses.

2 Jean Amos Comenius (1592-1670) foi um pensador checo que pregava um pacifismo democrático. Os expositores checos da conferência afirmam que o pensamento de Comenius ainda inspirava os programas escolares elaborados nesse início de século XX e representava o caminho escolhido pelo povo checo para se alcançar a paz.

3 Antônio Carneiro Leão foi diretor geral da instrução pública primária, normal e profissional no Rio de Janeiro de 1922 a 1926.

4 étudier successivement les données psychologiques indispensables pour bien poser la question, puis quelques-unes des solutions proposées ou déjà tentées pour aboutir à un résultat positif par l'enseignement et par l'éducation tout entière.

$5 \quad||$ est facile de voir que les diverses expériences pratiques tentées par les conférenciers en matière d'éducation pour la paix s'inspirent d'observations psychologiques ou aboutissent à des conclusions de cet ordre.

6 Quelques problèmes psychologiques de l'Éducation pour la paix.

$7 \quad$ L'étude scientifique des attitudes et des préjugés des enfants. Méthodes et résultats.

8 Questionnaire sur les sentiments des enfants relatifs à la Paix et à la guerre posé à 143 enfants et adolescents tchécoslovaques en février et mars 1927.

949 Pas de branche nouvelle, mais un nouvel esprit.

10 Les manuels d'histoire et les maitres enseigneront aussi à la jeunesse que le pacifisme n'est pas fait de soupirs sentimentaux; il ne consiste pas à fermer les yeux devant la réalité désagréable, c'est un travail systématique et hardi; il ne signifie pas seulement la guerre à la guerre mais plus encore, c'est-à-dire la guerre contre tout ce qui conduit à la guerre.

11 les expériences sont plus convaincantes que les paroles.

12 A Cruz Vermelha da Juventude foi uma das organizações que surgiram como apoio e viabilização desse método. No empreendimento da educação internacional, essa organização era responsável por traduzir os textos dos alunos e enviar as correspondências trocadas entre os escolares de diferentes nacionalidades.

$13[\ldots]$ avant d'en arriver au véritable internationalisme, il faut d'abord stimuler les sentiments de justice, de coopération, de soumission des intérêts égoïstes au but général. C'est là que se trouve la relation entre le self-government et le mouvement pacifiste.

14 Os Irmãos Checos se organizavam como a primeira igreja cristã relatada nos textos bíblicos e se consideravam filhos de um mesmo pai, o Pai celestial. Eles foram perseguidos a partir de 1620, época em que os protestantes constituíam três quartos do povo tcheco. Foram exilados em diversos países até poderem se reorganizar na Alemanha, na província de Saxe.

15 L'amour de la paix et l'hourreur de la violence, telle était la tradition de l'Unité des Frères tchèques.

16 quels adversaires, quels auxiliaires un éducateur animé d'un ideal de paix trouvait dans les tendances spontanées de l'enfant, dans ses instincts (...).

17 Apesar desta obra não ter sido traduzida para o Português, acreditamos que em alguma medida o trabalho de Bovet foi divulgado no Brasil já que, conforme registrado por Rochedieu (1967), 
em 1952 ele visita as cidades de São Paulo, Belo Horizonte e o estado da Bahia na qualidade de conferencista.

18 L'armée tout entière pourrait être décrite comme une manifestation de l'instinct social mis au service de l'instinct de lutte.

19 En fait, le symbole de la famille humaine, nous n'en trouverons jamais de plus beau, ni de plus satisfaisant pour l'esprit et pour le coeur à la fois, que celui du Père céleste. La religion de la fraternité humaine ne saurait en faire fi; elle ne saurait même à la longue- c'est notre conviction - s'en passer.

20 Ainsi, l'éducation pour la paix m'apparait supposer et impliquer à la fois l'éducation morale (la lutte contre le mal), l'éducation sociale (une initiation à la solidarité), l'éducation religieuse (une connaissance plus haute du Père céleste et de la famille humaine).

\section{Referências}

ABRAMOVAY, Miriam; RUA, Maria das Graças (Coord.). Violência nas escolas. Brasília: Unesco, Instituto Ayrton Senna, UNAIDS, Banco Mundial, USAID, Fundação Ford, CONSED, UNDIME, 2002.

ALMEIDA, Marilene Oliveira. O ensino de arte em Minas Gerais (1940-1960): diálogos e colaborações entre a arte e a educação nova. 2013. 226 f. Dissertação (Mestrado em Educação) - Programa de pós-Graduação em Educação, Universidade Federal de Minas Gerais. Disponível em: http://www.bibliotecadigital.ufmg.br/. Acesso em: 15 jun. 2016.

ASSIS, Raquel Martins. A formação da inteligência e da moralidade: o conceito de atividade em compêndios do século XIX. In: SANTIAGO, Ana Lydia; CAMPOS, Regina Helena de Freitas. Educação de crianças e jovens na contemporaneidade. Belo Horizonte: Editora PucMinas, 2011.

ASSIS, Raquel Martins; ANTUNES, Mitsuko Makino. Psiquismo na criança: Psicologia divulgada pela Imprensa educacional no Brasil (1930-1940). Psichologia Latina, Madrid, v. 5, n. 1, p. 21-30, 2014.

BOVET, Pierre (Dir.). La paix par l'école. Travaux de la Conférence Internationale de Prague, (16-29 avril). Genève: Bureau International d'Éducation; Prague: Société Pédagogique Comenius, 1927.

BOVET, Pierre. Quelques problèmes psychologiques de L'education pour la Paix. In: BOVET, Pierre (Dir.). La paix par l'école. Travaux de la conférence internationale de Prague, (16-29 avril). Genève: Bureau International d'Éducation; Prague: Société Pédagogique Comenius, 1927. 
A paz pela escola e as contribuições da Psicologia para os ideais da pedagogia pacificadora

BUREAU INTERNATIONAL D'ÉDUCATION. Premier cours spécial pour le personnel enseignant - Comment faire connaître la Société des Nations et développer l'esprit de coopération internationale? Compte-rendus des conférences donnés du 20 août au ler septembre 1928. Genève: Bureau International d'Éducation, 1928.

CAMPOS, Regina Helena; NEPOMUCENO, Denise. $\bigcirc$ funcionalismo europeu: Claparède e Piaget em Genebra, e as repercussões de suas idéias no Brasil. In: JACÓ-VILELA, Ana Maria; FERREIRA, Arthur; PORTUGAL, Francisco. História da Psicologia: rumos e percursos. Rio de Janeiro: Nau Editora, 2006.

CASSIMIR, R. L'Autonomie des écoliers (self-government). Une introduction à la Societé des Nations. In: BOVET, Pierre. (Org.) (1927). La paix par l'école. Travaux de la conférence internationale de Prague (16-29 avril). Genève: Bureau International d'Éducation; Prague: Société Pédagogique Comenius, 1927.

DELORS, Jacques (Org.). Educação: um tesouro a descobrir. Relatório para a Unesco da Comissão Internacional sobre Educação para o século XXI. Brasília: Unesco/Brasil, 2010.

FRANTA, Zdenek. Comment l'esprit de paix devrait-il se manifester dans les manuels d'histoire. In: BOVET, Pierre. (Org.) (1927). La Paix par l'école. Travaux de la conférence internationale de Prague (16-29 avril). Genève: Bureau International d'Éducation; Prague: Société 96 Pédagogique Comenius, 1927.

HENDRICH, J. L'Effort Pacifiste de Comenius. In: BOVET, Pierre. (Org.) (1927). La paix par I'école. Travaux de la Conférence Internationale de Prague, (16-29 avril). Genève: Bureau International d'Éducation; Prague: Société Pédagogique Comenius, 1927.

HOBSBAWM, Eric. Era dos extremos: o breve século XX (1914-1991). Companhia das Letras: São Paulo, 1995.

HOFSTETTER, Rita; RATCLIFF, Marc; SCHNEUWLY, Bernard. Cent ans de vie - La Faculté de Psychologie et des Sciences de l'Éducation, héritière de l'Institut Rousseau et de l'ère piagetienne 1912-2012. Genève: Georg Editeur, 2012.

JARES, Xesús. Educação para a paz: sua teoria e sua prática. 2. ed. rev. ampl. Porto Alegre: Artmed, 2002.

LOUREIRO, Clarice Moukachar Batista. "É possível uma educação para a paz?" A psicologia nas discussões sobre uma pedagogia pacificadora entre 1927 e 1934 na Europa. 2015. 102f. Dissertação (Mestrado em Educação) - Programa de pós-Graduação da Faculdade de Educação, Universidade Federal de Minas Gerais. Disponível em http:// www.bibliotecadigital.ufmg.br/. Acesso em: 9 ago. 2016. 
MAGNIN, Charles. Si tu veux la paix, cultive la justice! Jalons d'une histoire de l'éducation à la paix dans le cadre du Bureau International d'Éducation (1927-2001). In: AUDIGIER, François; BOTTANI, Norberto (Dir.). Education et vivre ensemble. Genève: Service de la recherche en éducation, 2002.

PARRAT-DAYAN, Silvia. Piaget e as instituições: o Instituto Jean-Jacques Rousseau, o BIE e o Centro Internacional de Epistemologia Genética. In: CAMPOS, Regina Helena; VIEIRA, Rita de Cássia (Org.). Instituições e Psicologia no Brasil. Rio de Janeiro: Nau Editora, 2008.

PASQUIER, Marcel du. Les efforts constructifs et les recommandations de la commission de coopération intellectuelle. In: BOVET, Pierre (Dir.). La paix par l'école. Travaux de la conférence internationale de Prague (16-29 avril). Genève: Bureau International d'Éducation; Prague: Société Pédagogique Comenius, 1927.

PIAGET, Jean. Introdução psicológica à educação internacional[1931] In: PARRAT, Silvia; TRYPHON, Anastasia. Jean Piaget: sobre a Pedagogia. São Paulo: Casa do Psicólogo, 1998.

PONGRATZ, Ludwig J. Abordagens descritiva e analítica: Dilthey vs. Ebbinghaus. In: BROZEK, Josef; MASSIMI, Marina. Historiografia da psicologia moderna. Edições Loyola, São Paulo, 1998. (Versão brasileira).

ROCHEDIEU, Edmond. Pierre Bovet (1878-1965). Obituary. Revue de théologie et de phi-

losophie, Zurich,v. 17, n. 3, 1967. Disponível em: www.e-periodica.ch. Acesso em: 22 jun. 2016.

RUCHAT, Martine. A Escola de psicologia de Genebra em Belo Horizonte: um estudo por meio da correspondência entre Edouard Claparède e Hélène Antipoff ( 1915 -1 940). Revista Brasileira de História da Educação, São Paulo, n. 17, p. 181-205, 2008.

VIDAL, Fernando. Le sujet et les frontières de la psychologie, XVIle-XXe siècle. Estudos e pesquisas em Psicologia, Rio de Janeiro, n. 1, v. 3, p. 4-13, 2003. Disponível em: www.e-publicacoes.ueri.br/index.php/revispsi/article/view/7774. Acesso em: 15 jun. 2016.

Ms. Clarice Moukachar Batista Loureiro Universidade Federal de Minas Gerais

Faculdade de Educação Centro de Documentação e Pesquisa Helena Antipoff - CDPHA I UFMG Fonte financiadora: CAPES E-mail | claricelou@gmail.com 
Artigo

A paz pela escola e as contribuições da Psicologia para os ideais da pedagogia pacificadora

Profa. Dra. Raquel Martins de Assis Universidade Federal de Minas Gerais Faculdade de Educação Centro de Documentação e Pesquisa Helena Antipoff - CDPHA / UFMG E-mail | rmassis.ufmg@gmail.com

Recebido 20 ago. 2016 Aceito 10 jan. 2017 